\title{
Endoscopic assessment of children with esophageal atresia: Lack of relationship of esophagitis and esophageal metaplasia to symptomatology
}

\author{
Julie Castilloux $M D^{1,3}$, Dorothée Bouron-Dal Soglio $M D^{2,4}$, Christophe Faure $M D^{1,4}$
}

J Castilloux, D Bouron-Dal Soglio, C Faure. Endoscopic assessment of children with esophageal atresia: Lack of relationship of esophagitis and esophageal metaplasia to symptomatology. Can J Gastroenterol 2010;24(5):312-316.

BACKGROUND: Late complications of esophageal atresia (EA), particularly esophagitis and Barrett's esophagus, are increasingly being recognized. With the exception of patients with dysphagia associated with esophageal stricture, it is unknown whether patient symptomatology can predict endoscopic findings.

METHODS: Data regarding the digestive symptoms of patients who were referred to the EA multidisciplinary clinic from October 2005 to October 2008, and underwent upper gastrointestinal endoscopic evaluation, were systematically collected. Macroscopic and histological findings were analyzed. Endoscopy was considered normal if no esophagitis, intestinal metaplasia or gastric metaplasia (GM) was discerned.

RESULTS: Sixty-three patients underwent endoscopy. Eighteen had dysphagia related to an esophageal stricture needing dilation and were subsequently excluded from the analysis. Forty-five patients (26 girls) with a median age of 7.3 years (range 0.4 to 17.9 years) were evaluated. Twenty-six patients (58\%) were normal at endoscopy, 14 patients (31\%) had esophagitis and 16 patients (36\%) had GM. No intestinal metaplasia or adenocarcinoma was detected. Six patients with abnormal endoscopy results were asymptomatic. No correlation between digestive symptoms and endoscopy results was found.

CONCLUSION: The present cross-sectional study showed that symptomatology was not predictive of abnormal endoscopy in EA patients. Esophagitis or GM may be discovered, even in the absence of symptoms, suggesting that physicians cannot rely solely on symptomatology to accurately evaluate the extent of these esophageal complications in this population.

Key Words: Barrett's esophagus; Endoscopic findings; Esophageal atresia; Esophagitis; Gastric metaplasia; Intestinal metaplasia

Cince the first successful surgery in 1941 (1), the survival of $\checkmark$ patients with esophageal atresia (EA) has greatly improved $(2-6)$. Subsequently, the follow-up of these patients has revealed gastrointestinal (GI) complications such as gastroesophageal reflux (GER), esophagitis and their related consequences (7-10), which were unrecognized 60 years previously.

Among these complications, one of the major concerns in the long-term GI follow-up is the increased incidence of gastric
Lévaluation endoscopique des enfants ayant une atrésie œsophagienne : L'absence de lien symptomatologique pour prédire l'œsophagite et la métaplasie œsophagienne

HISTORIQUE : Les complications tardives de l'atrésie œsophagienne (AO), notamment l'œsophagite et l'œsophage de Barrett, sont de plus en plus dépistées. À l'exception des patients ayant une dysphagie associée à une sténose œsophagienne, on ne sait pas si la symptomatologie des patients peut prédire les résultats endoscopiques.

MÉTHODOLOGIE : Les chercheurs ont colligé systématiquement les données portant sur les symptômes digestifs des patients aiguillés vers une clinique multidisciplinaire d'AO entre octobre 2005 et octobre 2008 et qui ont subi une évaluation endoscopique œsogastroduodénale. Ils ont analysé les observations macroscopiques et histologiques. Ils considéraient l'endoscopie comme normale s'ils n'y décelaient pas d'œsophagite, de métaplasie intestinale ou de métaplasie gastrique (MG).

RÉSULTATS : Soixante-trois patients ont subi une endoscopie. Dix-huit avaient une dysphagie liée à une sténose œsophagienne nécessitant une dilatation et ont ensuite été exclus de l'analyse. Quarante-cinq patients (26 filles) d'un âge moyen de 7,3 ans (plage de 0,4 à 17,9 ans) ont été évalués. Vingt-six (58\%) avaient des résultats normaux à l'endoscopie, 14 (31 \%) avaient une œsophagite et 16 (36 \%), une MG. Les chercheurs n'ont décelé aucune métaplasie intestinale et aucun adénocarcinome. Six patients dont les résultats endoscopiques étaient anormaux étaient asymptomatiques. Il n'y avait aucune corrélation entre les symptômes digestifs et les résultats de l'endoscopie.

CONCLUSION : La présente étude transversale a révélé que la symptomatologie ne permettait pas de prédire une endoscopie anormale chez des patients ayant une AO. On peut découvrir une œsophagite ou une MG même en l'absence de symptômes. Ainsi, les médecins ne pourraient pas se fier uniquement à la symptomatologie pour évaluer avec précision l'étendue des complications œsophagiennes au sein de cette population.

\footnotetext{
${ }^{1}$ Division of Gastroenterology and Department of Pediatrics; ${ }^{2}$ Department of Pathology; ${ }^{3}$ Centre Hospitalier Universitaire Laval, Laval;

${ }^{4}$ Centre Hospitalier Universitaire Sainte-Justine, Montréal, Québec

Correspondence: Dr Julie Castilloux, Division of Gastroenterology, Centre Hospitalier Universitaire Laval, 2705 Boulevard Laurier, Québec,

Québec G1V 4G2. Telephone 418-656-4141 post 48424, e-mail julie.castilloux@mail.chuq.qc.ca

Received for publication May 22, 2009. Accepted September 4, 2009
} 


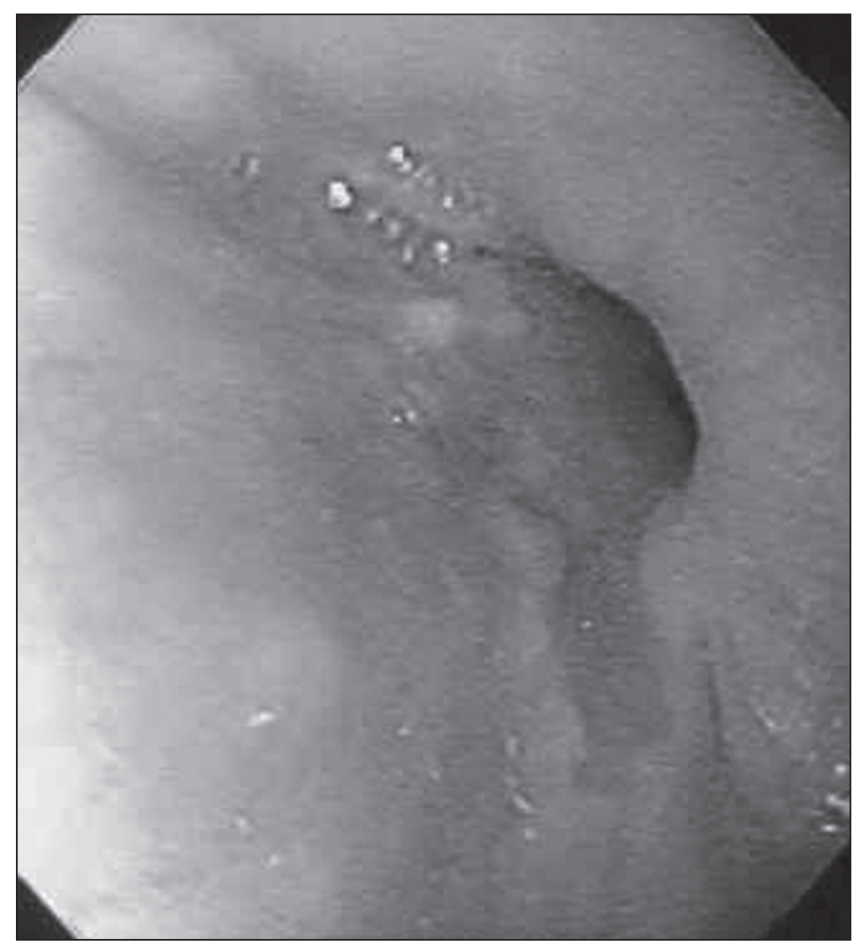

Figure 1) Barrett's esophagus, with its velvety-red tongue extending up in the esophagus from the proximal gastric folds at the gastroesophageal junction

endoscopic appearance would be very helpful in the clinical management of these patients.

Thus, the aims of the present cross-sectional study were to describe esophagitis, Barrett's esophagus (BE) and metaplasic features (macroscopic and microscopic) of the esophagus in a cohort of children with EA who were proposed a systematic endoscopic examination, and to verify whether a correlation between endoscopic observations and patient symptoms exists.

\section{METHODS}

\section{Patients}

In October 2005, a specialized EA clinic was created at the Centre Hospitalier Universitaire Sainte-Justine (Montreal, Quebec). Patients of all ages were invited to be followed by the clinic's multidisciplinary team. At their first visit, all patients were routinely proposed upper GI endoscopy if they were older than two years of age. If they were younger than two years of age, indication for endoscopy was based on symptoms (dysphagia, food impaction and/or hematemesis). The study period extended from October 2005 to October 2008.

Patients were excluded from the study if they had previously undergone gastric tube reconstruction, colonic interposition or esophagogastric dissociation. Patients with dysphagia associated with esophageal stricture needing dilation at endoscopy were not included in the analysis because they did not have esophageal biopsies taken when endoscopic dilation was performed.

\section{Clinical data collection}

Digestive symptoms were systematically recorded by asking specific predetermined questions. A data sheet was available at each visit. Questions were appropriate for all ages: patients (or parents) were

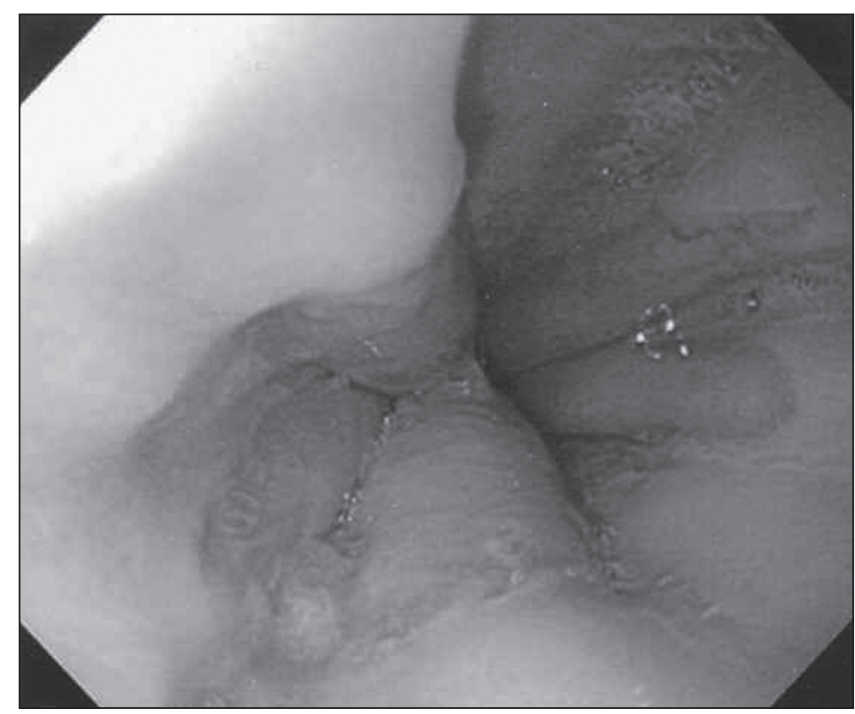

Figure 2) Proximal gastric folds in a patient with long-gap atresia (gastric pull-up). In this patient, the biopsies were taken at least $1 \mathrm{~cm}$ away from the gastroesophageal junction

asked whether they (or their child) experienced regurgitation or 'food coming up' (clinical GER), heartburn (pyrosis), trouble swallowing (dysphagia), pain with swallowing (odynophagia), food blockage (food impaction) and coughing at meals.

\section{Endoscopic data collection}

Macroscopic data were collected prospectively. Reports of macroscopic esophagitis were noted according to the SavaryMiller classification or the presence of endoscopically visible breaks in the esophageal mucosa at or immediately above the gastroesophageal junction (18). The BE macroscopic aspect was defined as velvety-red tongue extending up in the esophagus from the proximal gastric folds at the gastroesophageal junction (Figure 1). BE endoscopic aspect was differentiated from hiatal hernia or gastric pull-up by carefully delimiting the gastroesophageal junction, identified as the proximal margin of the gastric folds (Figure 2). Each patient systematically underwent at least one esophageal biopsy. When a BE macroscopic aspect was seen, at least one supplementary biopsy was systematically taken from the segment in question. Care was taken to accurately biopsy the esophageal mucosa and not the gastric mucosa. Biopsies were taken above the proximal gastric folds, at least $1 \mathrm{~cm}$ away from the gastroesophageal junction. Such caution was needed mostly in patients with long-gap atresia, where gastric pull-up was often noticed.

A total of eight different pediatric endoscopists evaluated the patients. A specialized endoscopic nurse was present for each endoscopy.

Both macroscopic esophagitis and BE had to be confirmed by histology to be considered for analysis in the present study.

\section{Pathology data}

Esophagitis was defined as the elongation of papillae and basal hyperplasia. Biopsies from endoscopically suspected esophageal metaplasia that showed a columnar epithelium were 'flagged' as BE. As proposed by the Montreal definition and classification of GER (18), endoscopically suspected esophageal 


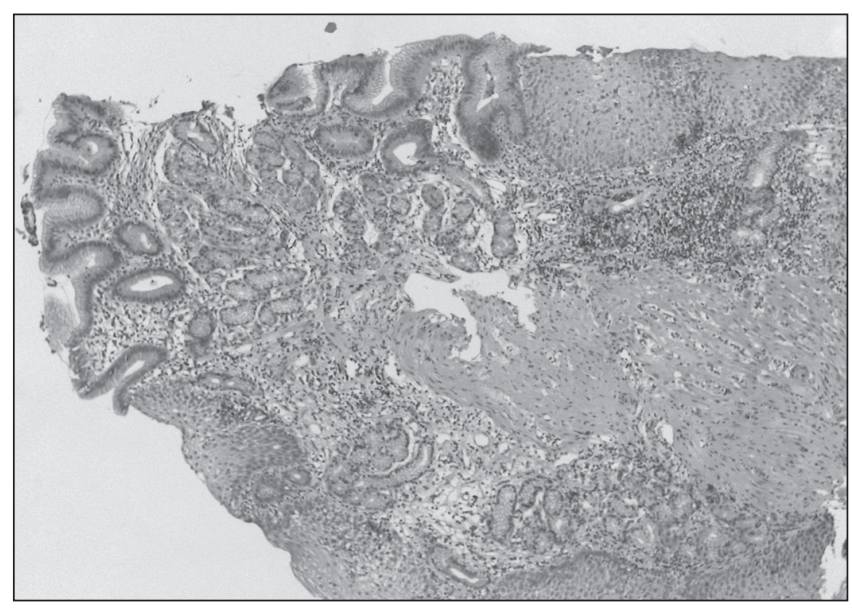

Figure 3) Biopsy showing esophageal metaplasia with gastric metaplasia (Barrett's esophagus/gastric metaplasia positive). Hematoxylin phloxine saffron stain, original magnification $\times 100$

metaplasia, both cardiac- and intestinal-type metaplasia should be included in the definition of BE $(18,19)$. Metaplasia type was defined as BE, gastric GM positive (GM+) (Figure 3) or $\mathrm{BE}$, specialized intestinal metaplasia positive (19-22). In biopsies for which metaplasia was suspected, Alcian blue dye was used to highlight goblet cells and readily distinguish intestinal metaplasia. One pathologist (DBDS) systematically reviewed all the biopsies that were previously analyzed by another pathologist who was a member of the department of pathology. Discrepancies in analyses were resolved by discussion, with final diagnosis established by consensus between the two participating pathologists.

\section{$\mathrm{pH}$ monitoring}

When a pH study was performed, the reflux index (23) was used as the criterion for acid reflux: for children younger than one year of age, the percentage of time at $\mathrm{pH}<4$ for more than $10 \%$, and for older than one year of age, the percentage of time for more than $5 \%$ were considered to be abnormal.

\section{Statistical analysis}

Endoscopy was considered normal if there was no evidence of macroscopic and microscopic esophagitis, no BE/GM+, and no $\mathrm{BE} /$ specialized intestinal metaplasia positive. Symptoms were analyzed according to endoscopic findings; differences between groups were analyzed by the $\chi^{2}$ test, with $\mathrm{P}<0.05$ considered to be statistically significant.

The study was approved by the local institutional board.

\section{RESULTS}

Sixty-three patients underwent endoscopy. No patient refused the evaluation. Eighteen patients needed dilation for esophageal stricture and were subsequently excluded from the analysis (Figure 4). The study group consisted of 45 patients (26 girls) with a median age of 7.3 years at the time of endoscopy (range five months to 17 years, 11 months). Thirty-seven patients (82\%) had type C atresia (24), 10 (22\%) had long-gap atresia, and 11 patients (24\%) had VACTERL (vertebral, anal, esophageal, renal, limb defects) association (Online Mendelian

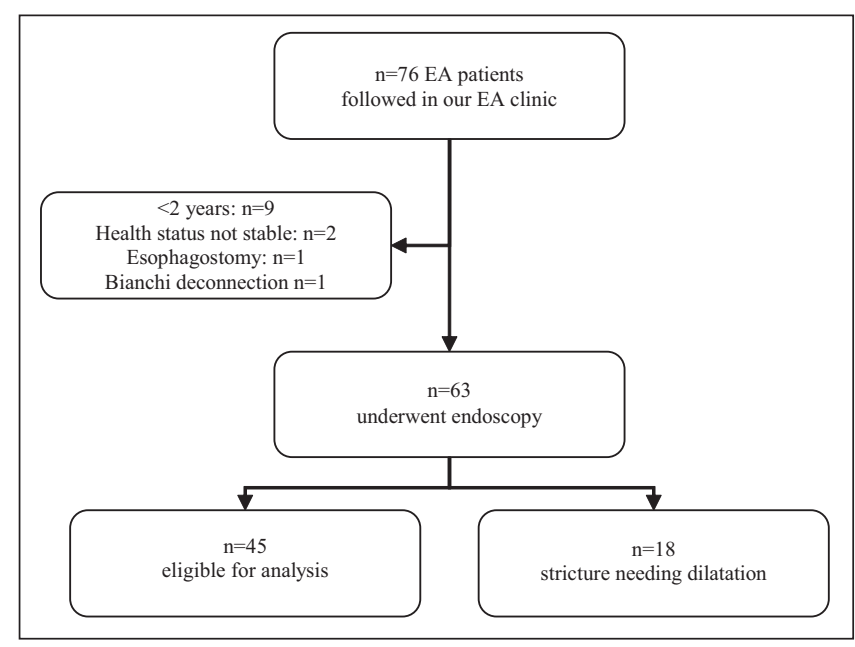

Figure 4) Patients included in the analysis. EA Esophageal atresia

Inheritance in Man 192350). Twenty patients (44\%) underwent a fundoplication procedure before the endoscopy and 10 (22\%) had a history of esophageal stricture needing dilation.

Twenty-six patients (58\%) were normal at endoscopy. Fourteen patients $(31 \%)$ had histologically proven esophagitis, and $16(36 \%)$ had GM (BE/GM+) (Figure 3). In the latter patient group, the mean age was 9.8 years (range 3.4 to 13.2 years), and six patients had long-gap atresia. No intestinal metaplasia, dysplasia or adenocarcinoma was found. As reported in Figure 5, both esophagitis and GM were encountered in patients four years of age and older.

$\mathrm{pH}$ monitoring was performed in 24 of the 63 patients. Of the 14 patients with esophagitis, six underwent $\mathrm{pH}$ monitoring, which revealed abnormal results in all patients who were not on antacid medication (ie, proton-pump inhibitors). Of the 16 patients with GM, seven underwent $\mathrm{pH}$ monitoring, with abnormal results in only three of these seven.

Twenty-eight patients (62\%) were symptomatic. The symptoms reported were dysphagia in $40 \%$, food impaction in $36 \%$, coughing during meals in $27 \%$, regurgitation in $20 \%$, pyrosis in $13 \%$ and odynophagia in $2 \%$.

Of 17 completely asymptomatic patients, six had abnormal endoscopy results. Of these six patients, four had both esophagitis and GM. In contrast, of the 28 symptomatic patients, 15 had normal endoscopic findings.

No association was found between the symptoms and endoscopic findings analyzed either as a whole (abnormal endoscopy) (Table 1) or separately (esophagitis or GM).

\section{DISCUSSION}

The present study was one of the largest pediatric endoscopic series of patients with EA (11-14,25). Our study was based on systematic endoscopic evaluation of all EA patients, with the intention of specifically screening for BE and esophagitis. Mucosal abnormalities at endoscopy were observed in 19 of 45 patients $(42 \%)$ in our cross-sectional study. Symptoms were reported by $62 \%$ of patients, but none could be identified as being statistically associated with an abnormal endoscopic finding. Furthermore, six asymptomatic patients had abnormal endoscopy results, reflecting the difficulty in adequately deciding which patients need to be investigated. 


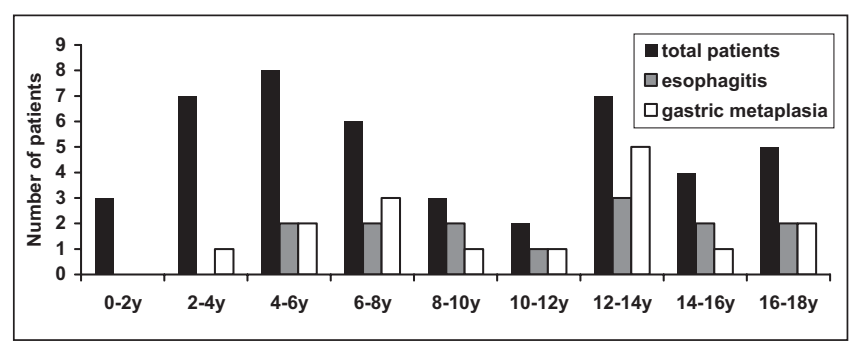

Figure 5) Distribution of esophagitis and gastric metaplasia according to age. y Years

Patients with strictures needing dilation were excluded from the analysis because the majority of them did not have biopsies at endoscopy - most gastroenterologists at our institution prefer not to perform an esophageal biopsy when performing a dilation. Furthermore, these patients had obvious symptoms requiring immediate attention. If patients with strictures had been included in the analysis, dysphagia would have been statistically associated with abnormal endoscopic findings but only due to cases of significant strictures requiring dilation.

In patients followed for EA in recent years, our attention has been focused on significant complications of GER, such as $\mathrm{BE}$ and esophageal adenocarcinoma. BE with intestinal metaplasia is a premalignant condition highly associated with an increased risk of esophageal adenocarcinoma $(26,27)$. The prevalence of $\mathrm{BE}$ with intestinal metaplasia is closely related to GER duration $(28,29)$. Moreover, a recent population-based study (30) has demonstrated the strong association between GER and the risk of esophageal carcinoma $(\mathrm{OR}=7.7)$. Taken together, these studies suggest that EA patients affected by severe, protracted GER are particularly exposed to the risk of developing severe complications from chronic esophageal acid exposure. Adenocarcinomas have previously been reported in 20-year-old (15) and 22-year-old (16) EA patients. The endoscopic screening of such complications or of lesions preceding these complications is, thus, warranted.

Fortunately, no intestinal metaplasia or adenocarcinoma was found in our population. However, 16 patients had GM. While long-term acid exposure contributes to carcinogenesis in $\mathrm{BE}$ with intestinal metaplasia (21), its effect on GM is less well defined. Some authors believe that GM is associated with adenocarcinoma $(11,12)$, whereas others do not $(25,31)$. However, in patients with EA, the increased incidence of GER beginning early in life with a possible lifelong evolution $(7,10)$ makes them a population at very high risk of GM transforming into intestinal metaplasia (19). Since the inception of our multidisciplinary clinic, five patients with GM have undergone subsequent endoscopy, with no intestinal metaplasia encountered. Whether prolonged, aggressive, acid suppression is beneficial in these situations remains to be determined. A long-term follow-up of these patients is warranted and is currently underway at the Centre Hospitalier Universitaire Sainte-Justine.

Hiatal hernia or gastric pull-up can complicate landmark recognition and can lead to erroneous diagnosis of GM (19), mostly in patients with long-gap atresia. In this regard, we specifically identified the esophageal mucosa by carefully delimiting the gastroesophageal junction, identified as the proximal margin of the gastric mucosal folds (Figures 1 and 2), as defined by Prague C \& M criteria (32). Moreover, only six of the 16 subjects
TABLE 1

Clinical symptoms according to endoscopic findings

\begin{tabular}{lcc}
\hline & \multicolumn{2}{c}{ Endoscopy results } \\
\cline { 2 - 3 } & Normal (n=26) & Abnormal (n=19) \\
\hline Regurgitation/clinical GER & $4(15)$ & $5(26)$ \\
Pyrosis & $2(8)$ & $4(21)$ \\
Dysphagia & $10(38)$ & $8(42)$ \\
Odynophagia & $1(4)$ & $0(0)$ \\
Food impaction & $10(38)$ & $6(32)$ \\
Cough at meals & $6(23)$ & $6(32)$ \\
Asymptomatic & $11(42)$ & $6(32)$ \\
\hline
\end{tabular}

Data are presented as $n$ (\%). $\chi^{2}$ test, no symptom with $P<0.05$. GER Gastroesophageal reflux

with GM had long-gap atresia. Therefore, we believe that the specimens diagnosed as GM were truly GM and not erroneously diagnosed gastric mucosa.

Finding specific symptoms associated with abnormal endoscopy would have been helpful. In their long-term follow-up of adults with EA, Taylor et al (33) investigated endoscopic abnormalities only in symptomatic patients and reported a $58 \%$ incidence of esophagitis and an $11 \%$ incidence of intestinal metaplasia. Based on our study, esophageal mucosal abnormalities can be observed in EA patients at endoscopy despite the absence of symptoms (six of 17 patients [35\%]), making the recommendation of endoscopic assessment based solely on symptomatology inappropriate.

On the other hand, our investigation shows that some symptomatic patients were completely normal at endoscopy. Symptoms such as dysphagia, odynophagia or food impaction can be related to esophageal dysmotility in this population of patients, as demonstrated by manometric studies $(12,34)$.

A limitation of the present study is the total number of biopsies taken because it did not strictly follow the guidelines for BE surveillance $(18,20)$. Therefore, we acknowledge that some GM or intestinal metaplasia may have been missed and that our results are most likely an underestimation of the true number of these conditions.

Another limitation is the sample size; therefore, it is possible that no association between symptoms and endoscopic findings could be statistically demonstrated because of an insufficient number of patients. However, Locke et al (35) noted that in a non-EA population of 1011 adults, symptoms were only weakly predictive of findings at endoscopy. In infants, the presence of esophagitis is difficult to predict on the basis of symptoms. Chadwick et al (36) reported a poor correlation between symptoms and histological changes. Salvatore et al (37) demonstrated that questionnaires are poorly predictive of GER disease severity because they do not correlate with esophageal acid exposure, measured by $\mathrm{pH}$-metry, and with esophagitis, evaluated by the histological analysis of esophageal biopsies.

\section{CONCLUSION}

Our study indicates that symptoms are not predictive of abnormal endoscopy in patients with EA. Furthermore, even in the absence of symptoms, abnormal findings may still be discovered. Many of these patients present with GM for which no exact modalities exist with regard to its follow-up and surveillance. Considering the high prevalence of GER 
in_this population, the systematic endoscopic follow-up and evaluation of esophageal biopsies in EA patients to accurately evaluate complications, response to treatment and outcomes are warranted. Close collaboration between gastroenterologists and pathologists should be established, lesions should be described according to standardized landmarks and biopsy samples should be taken with special care.

ACKNOWLEDGEMENTS: We thank all members of the EA Multidisciplinary Clinic at Centre Hospitalier Universitaire Sainte-Justine, especially Martine Pomerleau, specialized nurse at the clinic, Dr Guy Lapierre from the Division of Pulmonology and Dr Arie Bensoussan from the Division of Surgery, for their involvement in the clinic. We also thank Patricia Perreault for her excellent technical support in endoscopy.

\section{REFERENCES}

1. Haight C, Towslet H. Congenital atresia of osephagus with tracheoesophageal fistula. Extrapleural ligation of fistula and end-to-end anastomosis of esophageal segments. Surg Gynecol Obstet 1943;76:672-88.

2. Ein SH, Shandling B. Pure esophageal atresia: A 50-year review. J Pediatr Surg 1994;29:1208-11.

3. Okada A, Usui N, Inoue M, et al. Esophageal atresia in Osaka: A review of 39 years' experience. J Pediatr Surg 1997;32:1570-4.

4. Orford J, Cass DT, Glasson MJ. Advances in the treatment of oesophageal atresia over three decades: The 1970s and the 1990s. Pediatr Surg Int 2004;20:402-7.

5. Lopez PJ, Keys C, Pierro A, et al. Oesophageal atresia: Improved outcome in high-risk groups? J Pediatr Surg 2006;41:331-4.

6. Lilja HE, Wester T. Outcome in neonates with esophageal atresia treated over the last 20 years. Pediatr Surg Int 2008;24:531-6.

7. Engum SA, Grosfeld JL, West KW, et al. Analysis of morbidity and mortality in 227 cases of esophageal atresia and/or tracheoesophageal fistula over two decades. Arch Surg 1995;130:502-508; discussion 508-9.

8. Deurloo JA, Ekkelkamp S, Bartelsman JF, et al. Gastroesophageal reflux: Prevalence in adults older than 28 years after correction of esophageal atresia. Ann Surg 2003;238:686-9.

9. Kovesi T, Rubin S. Long-term complications of congenital esophageal atresia and/or tracheoesophageal fistula. Chest 2004;126:915-25.

10. Koivusalo A, Pakarinen MP, Rintala RJ. The cumulative incidence of significant gastro-oesophageal reflux in patients with oesophageal atresia with a distal fistula - a systematic clinical, $\mathrm{pH}$-metric, and endoscopic follow-up study. J Pediatr Surg 2007;42:370-4.

11. Lindahl H, Rintala R, Sariola H. Chronic esophagitis and gastric metaplasia are frequent late complications of esophageal atresia. J Pediatr Surg 1993;28:1178-80.

12. Somppi E, Tammela O, Ruuska T, et al. Outcome of patients operated on for esophageal atresia: 30 years' experience. J Pediatr Surg 1998;33:1341-6.

13. Schalamon J, Lindahl H, Saarikoski H, et al. Endoscopic follow-up in esophageal atresia - for how long is it necessary? J Pediatr Surg 2003;38:702-4.

14. Krug E, Bergmeijer JH, Dees J, et al. Gastroesophageal reflux and Barrett's esophagus in adults born with esophageal atresia. Am J Gastroenterol 1999;94:2825-8.

15. Adzick NS, Fisher JH, Winter HS, et al. Esophageal adenocarcinoma 20 years after esophageal atresia repair. J Pediatr Surg 1989;24:741-4.

16. Pultrum BB, Bijleveld CM, de Langen ZJ, et al. Development of an adenocarcinoma of the esophagus 22 years after primary repair of a congenital atresia. J Pediatr Surg 2005;40:e1-4.
17. Alfaro L, Bermas H, Fenoglio M, et al. Are patients who have had a tracheoesophageal fistula repair during infancy at risk for esophageal adenocarcinoma during adulthood? J Pediatr Surg 2005;40:719-20.

18. Vakil N, van Zanten SV, Kahrilas P, et al. The Montreal definition and classification of gastroesophageal reflux disease: A global evidence-based consensus. Am J Gastroenterol 2006;101:1900-20.

19. Hassall E. Cardia-type mucosa as an esophageal metaplastic condition in children: "Barrett esophagus, gastric mucosa-positive?" J Pediatr Gastroenterol Nutr 2008;47:102-6.

20. Wang KK, Sampliner RE. Updated guidelines 2008 for the diagnosis, surveillance and therapy of Barrett's esophagus. Am J Gastroenterol 2008;103:788-97.

21. Souza RF, Shewmake K, Terada LS, et al. Acid exposure activates the mitogen-activated protein kinase pathways in Barrett's esophagus. Gastroenterology 2002;122:299-307.

22. Dvorak K, Fass R, Dekel R, et al. Esophageal acid exposure at $\mathrm{pH}<$ or $=2$ is more common in Barrett's esophagus patients and is associated with oxidative stress. Dis Esophagus 2006;19:366-72.

23. Rudolph CD, Mazur LJ, Liptak GS, et al. Guidelines for evaluation and treatment of gastroesophageal reflux in infants and children: Recommendations of the North American Society for Pediatric Gastroenterology and Nutrition. J Pediatr Gastroenterol Nutr 2001;32(Suppl 2):S1-31.

24. Gross R. Surgery of Infancy and Childhood. Philadelphia: WB Saunders Company, 1953.

25. Deurloo JA, Ekkelkamp S, Taminiau JA, et al. Esophagitis and Barrett esophagus after correction of esophageal atresia. J Pediatr Surg 2005;40:1227-31.

26. Drewitz DJ, Sampliner RE, Garewal HS. The incidence of adenocarcinoma in Barrett's esophagus: A prospective study of 170 patients followed 4.8 years. Am J Gastroenterol $1997 ; 92: 212-5$.

27. Falk GW. Barrett's esophagus. Gastroenterology 2002;122:1569-91.

28. Eisen GM, Sandler RS, Murray S, et al. The relationship between gastroesophageal reflux disease and its complications with Barrett's esophagus. Am J Gastroenterol 1997;92:27-31.

29. Lieberman DA, Oehlke M, Helfand M: Risk factors for Barrett's esophagus in community-based practice. GORGE consortium. Gastroenterology Outcomes Research Group in Endoscopy. Am J Gastroenterol 1997;92:1293-7.

30. Lagergren J, Bergstrom R, Lindgren A, et al. Symptomatic gastroesophageal reflux as a risk factor for esophageal adenocarcinoma. New Engl J Med 1999;340:825-31.

31. Sampliner RE. Practice guidelines on the diagnosis, surveillance, and therapy of Barrett's esophagus. The Practice Parameters Committee of the American College of Gastroenterology. Am J Gastroenterol 1998;93:1028-32.

32. Sharma P, Dent J, Armstrong D, et al. The development and validation of an endoscopic grading system for Barrett's esophagus: The Prague C \& M criteria. Gastroenterology 2006;131:1392-9.

33. Taylor AC, Breen KJ, Auldist A, et al. Gastroesophageal reflux and related pathology in adults who were born with esophageal atresia: A long-term follow-up study. Clin Gastroenterol Hepatol 2007;5:702-6.

34. Tomaselli V, Volpi ML, Dell'Agnola CA, et al. Long-term evaluation of esophageal function in patients treated at birth for esophageal atresia. Pediatr Surg Int 2003;19:40-3.

35. Locke GR, Zinsmeister AR, Talley NJ. Can symptoms predict endoscopic findings in GERD? Gastrointest Endosc 2003;58:661-70.

36. Chadwick LM, Kurinczuk JJ, Hallam LA, et al. Clinical and endoscopic predictors of histological oesophagitis in infants. J Paediatr Child Health 1997;33:388-93.

37. Salvatore S, Hauser B, Vandemaele K, et al. Gastroesophageal reflux disease in infants: How much is predictable with questionnaires, $\mathrm{pH}$-metry, endoscopy and histology? J Pediatr Gastroenterol Nutr 2005;40:210-5. 


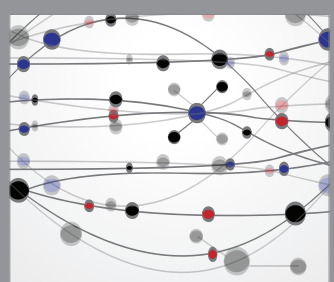

The Scientific World Journal
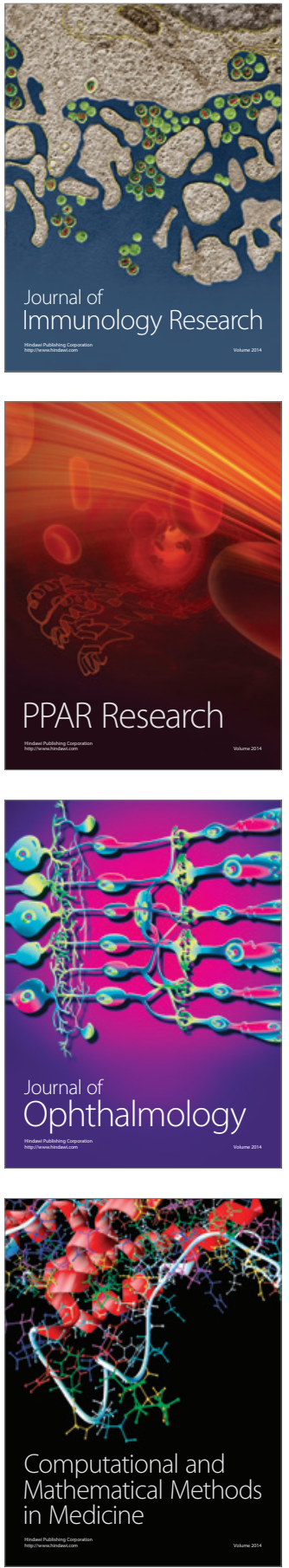

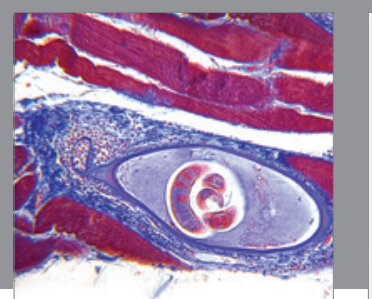

Gastroenterology Research and Practice

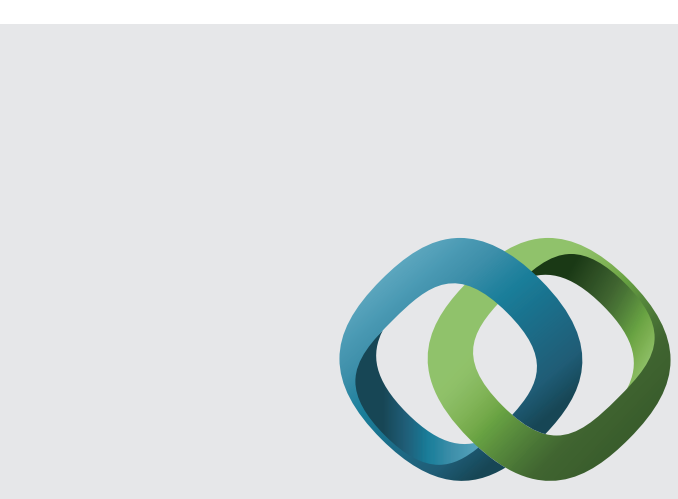

\section{Hindawi}

Submit your manuscripts at

http://www.hindawi.com
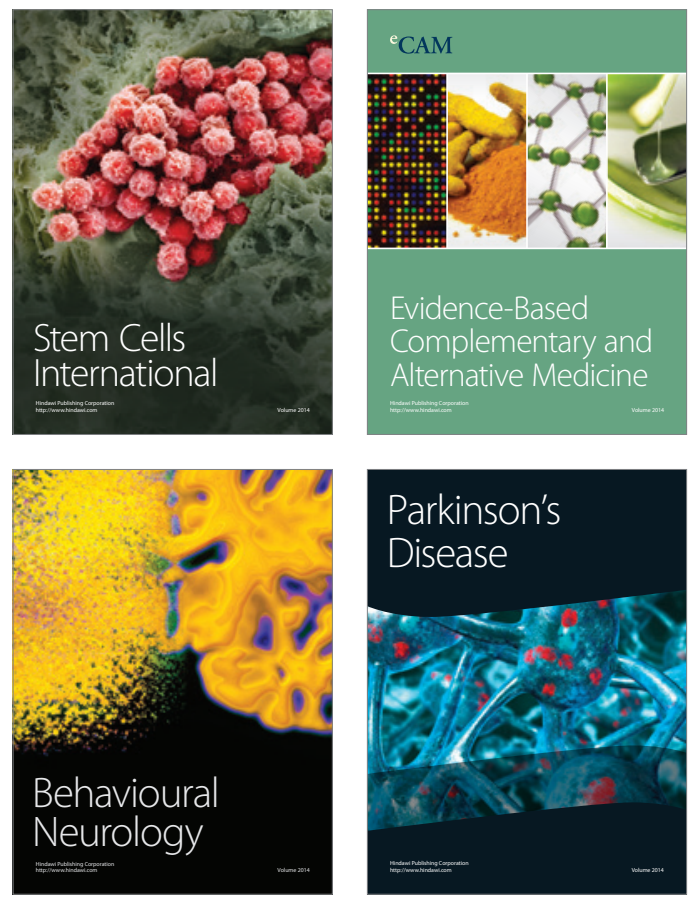
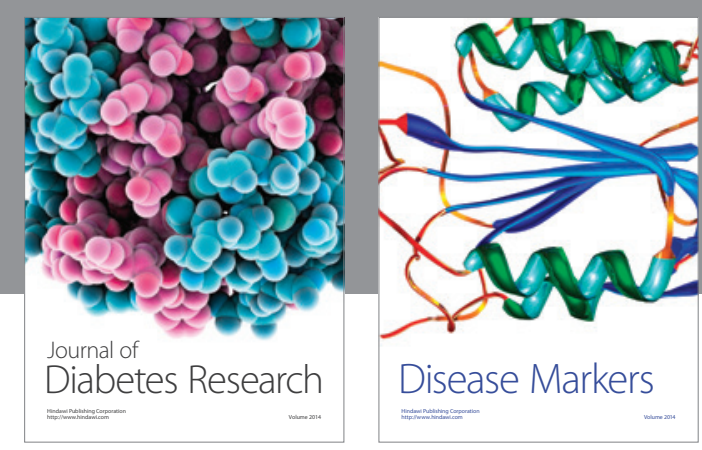

Disease Markers
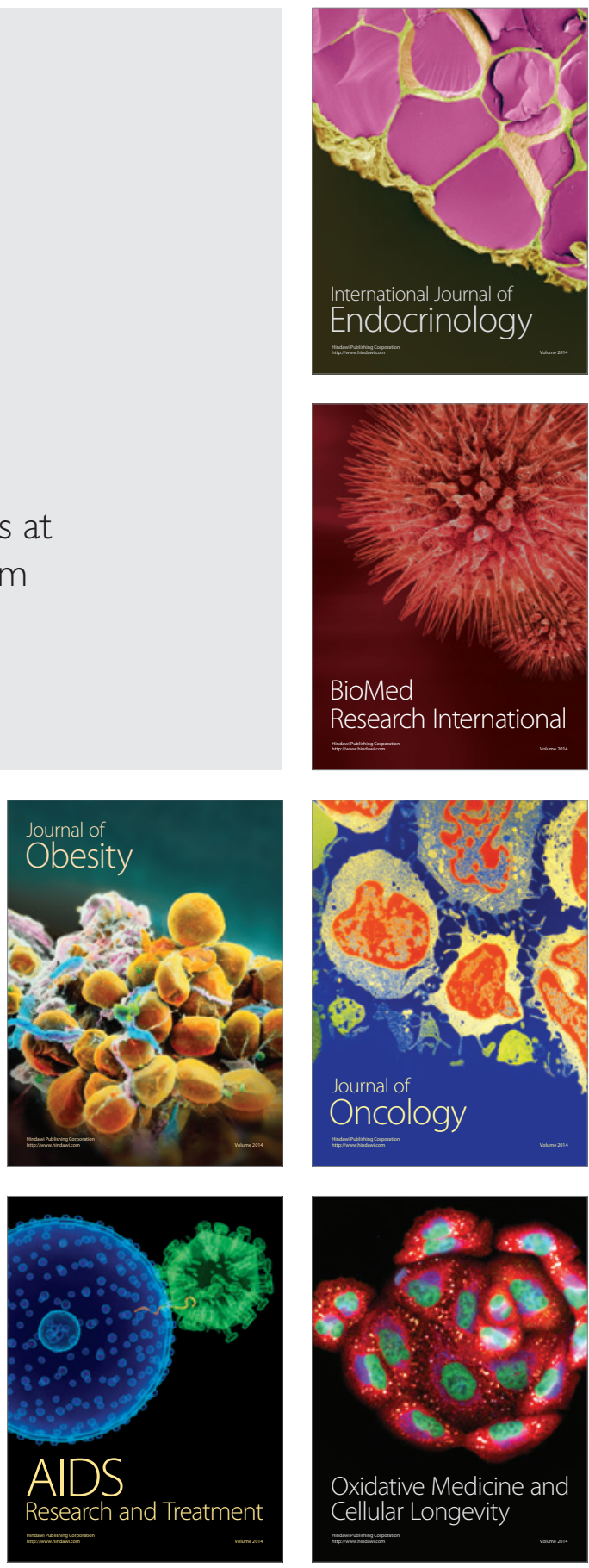